\title{
Uma Análise de Semelhanças e Diferenças na Tradução de TeXtos Técnicos, Jornalísticos E LITERÁRIOS
}

\author{
(Translation Research on Similarities and Differences in Technical, \\ Journalistic and Literary Texts)
}

\author{
Diva Cardoso de CAMARgo \\ (Universidade Estadual Paulista - UNESP/SJRP)
}

Resumo: Por meio da utilização de corpus de textos técnicos, jornalísticos e literários escritos originalmente em inglês e traduzidos para o português, pode-se efetuar uma análise das soluções propostas pelos tradutores ao lidarem com semelhanças e diferenças lingüísticas e culturais dos textos de partida e de chegada. Com esse intuito, aplicou-se o modelo descritivo-comparativo sugerido por Aubert (1984, 1998), o qual se origina das categorias de Vinay e Darbelnet ( $\{1958,1977\}$ 1995), a fim de, primeiramente, identificar e, depois, classificar os procedimentos ou modalidades empregadas na tradução desses gêneros textuais. Registraram-se como modalidades de maior incidência nos três corpora: a tradução literal, a transposição e a modulação. Em virtude de a alta freqüência da tradução literal ocorrer em textos técnicos e, contrariamente ao esperado, incidir com proporção ainda maior em textos jornalísticos, poder-se-ia inferir uma tendência para automatismos na tradução desses dois tipos de textos. Já a necessidade de um emprego acentuado da modulação e da transposição com modulação em textos literários poderia ser decorrente de uma participação mais ativa do tradutor na tentativa de escapar da literalidade e proceder a uma maior reelaboração, a fim de passar características normalmente associadas à linguagem do romance.

PalaVRas-ChaVE: Tradução técnica; Tradução jornalística; Tradução literária; Estudos de tradução baseados em corpus.

ABSTRACT: By using corpus of technical, journalistic and literary texts, originally written in English and translated into Portuguese, we may analyse the prevailing strategies employed by the translators when dealing with similarities and differences of source and target texts, languages and cultures. With this purpose in mind, we applied the descriptive-comparative model suggested by Aubert (1984, 1998). This model

D.E.L.T.A., 20:1, 2004 (1-25) 
adapts the categories proposed by Vinay and Darbelnet ((1958, 1977)1995), in order to first identify then classify the procedures or modalities that characterise the translation of these text genres. According to data comparison, the most common modalities in the three corpora are found to be literal translation, transposition, and modulation. Because the high frequency of literal translation appears in technical texts and, contrary to what was expected, also occurs in journalistic texts with even higher percentage, we may infer a tendency towards automatism in the translation of these two text types. On the other hand, the greater need for modulations and transpositions with modulation may be said to be related to the literary text translators' more active participation in attempting to escape from literalism towards re-elaboration, in order to convey features commonly attached to the language of the novel.

KEY-WORDS: Technical translation; Journalistic translation; Literary translation; Corpus-based translation research.

\section{Introdução}

Como os Estudos Lingüísticos têm apresentado, atualmente, uma preocupação muito mais descritiva do que prescritiva, poderia apontar-se para um direcionamento não só no que o tradutor sabe sobre a língua de partida (LP) e a língua de chegada (LC), mas para um maior interesse no que o tradutor faz com a LC. Por essa razão, tem-se observado uma tendência em tomar por base exemplos autênticos, aumentando a necessidade do uso de corpora não somente para trabalhos de cunho lingüístico, em todos os seus níveis (morfológico, lexical, sintático, semântico e até pragmático) como, em especial, tem crescido acentuadamente o interesse pelo emprego de corpora compostos de textos originais (TOs) e textos traduzidos (TTs).

A necessidade de corpus para o estudo da língua e da tradução parece, de uma maneira geral, partir da variação intra- e interlingüística. Como enfatiza Marcuschi:

a língua, sabidamente, não é um conjunto de rotinas e sim um contínuo muito diversificado e complexo de atividades sócio-interativas pelas quais os indivíduos em condições específicas produzem sentidos públicos partilháveis. Portanto, inerente a todas as línguas humanas, a variação é incontornável e torna condição necessária a utilização de corpora lingüísticos por parte de quem se dedica ao estudo de atividades lingüísticas situadas. (2001:1) 
Outrossim, a utilização de corpora para os Estudos da Tradução também é valorizada por Tymoczko (1998) ao afirmar que essa nova abordagem é importante para a sustentação e o desenvolvimento da disciplina neste século. A autora ressalta a importância de se visualizar o maior número possível de tipos de corpora para serem empregados em pesquisas em tradução, bem como enfatiza a necessidade de se estabelecer questões que possam ser investigadas em um corpus e métodos que possam ser utilizados, para se obter tanto resultados teóricos quanto práticos.

Procuraremos demonstrar, aqui, algumas das potencialidades de análise a partir do uso de corpus de TOs/TTs. No entanto, ressalte-se que, ao adotar uma dentre muitas das possíveis abordagens para a realização de um estudo descritivo-comparativo das estruturas de superfície entre TO/ TT, este trabalho e o modelo no qual se baseia não contêm em si qualquer implicação específica sobre a natureza da linguagem e do par de línguas em estudo. Conviria, também, destacar que uma abordagem técnica não se coloca em contraposição mas, certamente, em relação de complementaridade com as abordagens mais textuais ou antropológicas.

Nesse sentido, os estudos empíricos baseados em corpora têm-se tornado cada vez mais variados, explorando desde o conceito de mudança lingüística (descrito por Catford [1965] como desvio da correspondência formal) a investigações de características universais da linguagem da tradução e seu impacto ideológico. Baker (1999) enfatiza que as técnicas de análise de corpora permitem validar pressupostos teóricos sobre a tradução, como por exemplo, as concepções de Even-Zohar, Toury, Pym e Frawley, de que existem diferenças significativas entre a linguagem da tradução e a linguagem original. $\mathrm{Na}$ tradição dos estudos descritivos iniciada por Even-Zohar (1978) com a teoria dos polissistemas, o foco volta-se para padrões que regem o sistema da tradução literária em interação com os demais sistemas de produção textual de uma determinada cultura de chegada. Toury (1978), com o conceito de normas, é visto por Magalhães (2001:94) como "um dos primeiros teóricos a lançar a semente para as pesquisas em tradução baseadas em corpora, nos moldes sugeridos por Baker", porquanto acredita o autor na relevância de se comparar a natureza das normas que regem os TTs em relação às normas que regem os textos não-traduzidos. Por sua vez, Pym (1993:82) é de opinião que uma dada cultura, ainda que com sua especificidade e originalidade, possa ser estudada em função das traduções que nela circulam. Também integrando 
essa perspectiva, Frawley (1984), após ter definido a tradução como um 'terceiro código' emergente da consideração bilateral dos códigos matriz e alvo, sugere que as futuras teorias se concentrem na tradução como questão epistemológica, focalizando na informação nova que emerge da recodificação, uma vez que o foco semântico da preservação do sentido mostrou-se pouco elucidativo (2000:262). Desse modo, partindo do reconhecimento da tradução enquanto espaço diferencial que deve ser privilegiado na cultura de chegada, Baker (1993) considera a tradução como objeto de pesquisa per se, e elege como quadro metodológico para pesquisa a abordagem da Lingüística de Corpus.

Amplia-se, pois, a necessidade de estudos sistemáticos baseados em corpora, que permitam um melhor entendimento das possibilidades e das limitações das trocas lingüísticas e culturais ocorridas no processo tradutório, uma melhor compreensão das convergências e divergências entre a LP e a LC, bem como uma percepção mais nítida do papel do tradutor e sua influência no processo tradutório. Como, até o presente, a literatura especializada mostra estudos apenas pontuais sobre as categorias de tradução, evidencia-se a necessidade de investir numa pesquisa mais ampla, que passe a abarcar um universo de amostragem de três tipologias textuais distintas (técnica, jornalística e literária), a qual poderia levar a uma análise de tendências apresentadas pelos tradutores e de uma possível existência de praxe tradutória na relação inglês $\rightarrow$ português.

Esta investigação também integra uma linha de pesquisa junto ao CITRAT - Centro Interdepartamental de Tradução e Terminologia, da FFLCH/USP. A referida linha, por ser de maior abrangência, propõe-se a indicar uma via de abordagem que contribua para o estabelecimento de uma tipologia da tradução interlingual.

\section{Perspectiva teórica}

Mesmo tendo-se justificado, acima, a relevância de pesquisas baseadas em corpus de TOs/TTs, o embasamento teórico de um trabalho que se direcione para uma tipologia textual na tradução encontra, de imediato, problemas com a conceituação de equivalência textual, passando a requerer algumas considerações preliminares. Apresentar, todavia, um tratamento teórico detalhado, abarcando esse conceito dentro da ótica das duas 
principais correntes da Tradução: a teoria de base lingüística e a teoria de base textual e pós-estruturalista, seria por demais extenso e fugiria do âmbito deste estudo, fazendo-se, pois, necessário operar com recortes voltados para as especificidades da linha de pesquisa em que se insere a presente investigação.

É sabido que, na contínua busca pela equivalência no decorrer dos séculos, as tendências em favor de uma fidelidade à forma ou ao conteúdo têm sofrido alternâncias e a qualidade das traduções tem sido, historicamente, avaliada quanto a julgamentos voltados para a exatidão, fidelidade, adequação e outros, os quais carecem de melhor definição. Em anos mais recentes, o conceito de equivalência vem apresentando mudanças consoante o enfoque dado pelas diferentes abordagens teórico-metodológicas. Conforme as diversas posições adotadas pelos teóricos, o conceito sofre alterações, dentre elas podem citar-se: a 'equivalência dinâmica vs. equivalência formal' em Nida (1964), a 'equivalência textual vs. correspondência formal' em Catford (1965), a 'equivalência na mensagem e na situação’ em Vinay \& Darbelnet (1958; 1977), o ‘principio do efeito equivalente' em Newmark (1981), a 'equivalência funcional' em Reiss (1976/ 1989), a 'aceitabilidade' em Toury (1995), a 'equivalência pragmática' em Baker (1997).

Desse modo, é a partir de 1960, com o avanço dos estudos lingüísticos, que se expande o conceito de equivalência. Para a abordagem estruturalista, o conceito básico, ponto de confluência das propostas de diversos autores (dentre eles: Nida, Catford, Vinay \& Darbelnet) é o de que a tradução tem por objetivo reproduzir o conteúdo de um texto em outro texto, vazado em outra língua, tal reprodução sendo constituída pela equivalência de sentido. Assim, a presença ou ausência de tal equivalência confirma ou invalida o êxito do processo tradutório. Por essa perspectiva, a teoria de base estruturalista considera o TO como o ponto de partida, e estabelece parâmetros para medir diferenças lingüísticas e extralingüísticas entre os TO/TT.

Mais especificamente no caso de Vinay, ao abordar a equivalência tradutória em seu artigo "La Traducción Humana" (1976:161), declara ele que, para mantê-la, é necessário um compromisso de fidelidade com a mensagem e seus elementos semânticos e estilísticos. Também Vinay e Darbelnet estabelecem, na edição renovada e corrigida do Stylistique Comparée du Français e de l'Anglais (1977:22), que "a equivalência entre dois textos tem por base a equivalência de situação." Dentre os autores que, 
anteriormente, tentaram descrever o ato tradutório, os modelos por eles apresentados são, via de regra, exclusivamente teóricos. Fundamentandose nas concepções saussurianas, Vinay e Darbelnet são os primeiros, na literatura disponível, a aplicarem a Lingüística às categorias de tradução numa abrangência detalhada e sistemática, levando em conta a complexidade do ato tradutório. Embora os dois professores canadenses apresentem uma série de conversões esmeradas para cada uma das categorias propostas, não incorporam os elementos pragmáticos necessários a uma comunicação total.

As diferentes concepções teóricas citadas, propostas por Nida, Catford, Vinay e Darbelnet, Newmark, Reiss, Toury, e Baker, admitem alguma noção de equivalência, porquanto compreendem alguma noção de sentido determinável que pode ser transferido para outro sistema de significados. Atualmente a perspectiva lingüística vem sendo questionada por uma abordagem dinâmica que inclui o leitor do TC. Também a tradução passa a ser considerada como uma via possível no processo de comunicação entre duas culturas. Tendo o trabalho do tradutor adquirido maior relevância política, passou-se a exigir do profissional uma equivalência e uma sensibilidade especiais na tradução de declarações governamentais (a 'equivalência pragmática' em Baker, 1997). Por outro lado, ainda que o campo de interesse do plano micro para o macro venha sendo gradualmente ampliado, há evidências empíricas que mostram a pertinência de uma abordagem mais 'estritamente lingüística', quer levando em conta a crescente utilização da tradução com o auxílio do computador, quer apontando para o distanciamento existente entre a teoria e a prática tradutória. Conforme atesta Aubert (1998:101), destacam-se:

\footnotetext{
"De um lado, os progressos na tradução assistida por computador nesses últimos 1015 anos, que, em grande medida, derivam da montagem de algoritmos interlinguais operativos baseados na estrutura lingüística interna.

De outro lado, '... constitui fato empírico que na labuta diária dos tradutores profissionais a tradução é uma operação centrada na palavra, e para sua execução os tradutores recorrem a dicionários, tesouros e assemelhados como a primeira ferramenta externa. Indubitavelmente, essa não é toda a verdade. Mas poder-se-ia ousar sugerir que é uma parte significativa da verdade observada'. ${ }^{1}$ "
}

1 Tradução proposta por Gehring (1998:27) de: "in the everyday work of professional translators, translation is (or is felt to be) very much a word-centred operation, resorting to dictionaries, thesauri, and the 
Pelo exposto, observa-se que a tradução vem passando por uma reestruturação conceitual que a coloca no centro do debate contemporâneo sobre processos de transmissão cultural e suas relações com a linguagem, o que enfatiza o caráter transformador e interpretativo da atividade tradutória. A tradução interlingual se processa entre dois complexos língua/ cultura e a efetiva condução do ato tradutório envolve, evidentemente, não apenas o léxico e a sintaxe, mas a totalidade do texto, texto esse que incorpora em si uma determinada concepção da realidade e, para além do texto, as culturas, ideologias e realidades psico-sociais lato sensu. Mais ainda, para que o sentido do original seja, de alguma forma resgatado na operação tradutória, constitui tarefa do tradutor a busca por correspondência não apenas léxico-sintáticas, mas por uma interpretação e reformulação de um complexo sócio-lingüístico e antropo-cultural. Sob qualquer pespectiva teorizante, porém, a tradução sempre se expressará em orações, sintagmas e palavras. E, são precisamente os componentes estritamente lingüísticos (léxico e gramática) de uma tradução que permitem que a investigação do processo tradutório vá além da introspecção e do "apelo ao ouvido" (Gehring, 1998).

No presente estudo, defende-se a idéia de que uma observação mais detalhada do microcosmo constituído pelos mecanismos lingüísticos frásticos e sub-frásticos, que se manifestam em todo e qualquer ato tradutório poderá contribuir, através de indícios comprováveis estatisticamente, para aumentar a nossa percepção das similaridades e diferenças, das aproximações e distanciamentos entre duas línguas e duas culturas que se realizam na tradução.

\section{Método empregado na investigação}

O encaminhamento deste trabalho reveste-se, necessariamente, de uma natureza comparativa que, para a sua correta execução, exige um modelo descritivo que permita medir e quantificar o grau de diferenciação lingüística entre o TO e o TT, facultando, desse modo, a organização e a preparação de dados para o tratamento estatístico.

like as the primary external tool in their daily work. Indisputably, this is not the entire truth; far from it. But one might perhaps dare to suggest that it is a significant part of the perceived truth..." (Aubert, 1998:122) 
Por prestar-se a essa finalidade, adotou-se como método a proposta das modalidades de tradução sugerida por Aubert (1984, 1998). Essa versão atual do modelo baseou-se na sistematização das categorias estabelecidas por Vinay e Darbelnet (โ1958, 1977], 1995) e em algumas modificações sugeridas por Vinay (1968); contudo, como o modelo anterior apresenta algumas lacunas e determinadas definições mostram-se difíceis de serem operacionalizadas, fundamentou-se também a análise na reformulação do modelo proposta por Aubert. Ambos os modelos concebem as categorias numa escala, desde uma espécie de "grau zero da tradução" até um ponto em que a equivalência atinge o limiar do traduzível. Entre esses dois extremos, agrupam-se duas grandes categorias: a tradução direta (em que a passagem da LP para a LC é feita sem muita elaboração ou mudança de forma), e a tradução oblíqua (que envolve mudanças formais das estruturas lingüísticas e atém-se mais ao conteúdo e estilo). O modelo Aubert reparte a tradução direta em quatro modalidades básicas, com os respectivos códigos $^{2}$ : (02) transcrição, (03) empréstimo, (04) decalque e (05) tradução literal. Já a tradução oblíqua sugere que, com esse tipo de tradução, é que se realiza o ato tradutório propriamente dito, pois compreende as seguintes modalidades: (06) transposição, (07) explicitação/implicitação, (08) modulação, (09) adaptação e (10) tradução intersemiótica. Também o novo modelo considera quatro desdobramentos: (01) omissão, (11) acréscimo, (12) erro e (13) correção, além da possibilidade da co-ocorrência de várias categorias.

Para uma avaliação do grau de diferenciação, isto é, do grau de proximidade/distância entre o TO e o TT, formulou-se a pergunta de pesquisa de "quantos $\%$ do TO reaparecem no TT sob a forma de determinada modalidade?"

Como a unidade de contagem dos itens lexicais compreendidos pelas modalidades necessita de critérios que permitam uma operacionalização num modo o mais coerente possível tanto entre diferentes pesquisadores como entre a LP e a LC, escolheu-se a entidade 'palavra' na sua concepção tradicional, registrada na língua escrita pelo uso de espaços em branco e pelos verbetes no dicionário.

\footnotetext{
2 A definição e exemplos das modalidades de maior freqüência encontram-se no item 3. Resultados e discussão, a seguir.
} 
Quanto à seleção do material para compilação dos corpora, os dezoito TOs e os respectivos TTs encontram-se elencados nas Referências Bibliográficas, item $A$. Cada corpus compreende seis textos, cada um com quinhentos itens lexicais ${ }^{3}$ que, ao serem levantados em relação aos correspondentes itens lexicais dos seis TTs, somam um total de três mil itens lexicais na LP. No total geral, os corpora de textos técnicos, jornalísticos e literários contam com nove mil itens lexicais na LP mais os correspondentes itens lexicais na LC.

No tocante aos procedimentos para o levantamento e quantificação de dados, seguiu-se de acordo com o princípio adotado nas investigações anteriores da linha de pesquisa, aplicando-se o modelo Aubert, após selecionar as páginas e sortear os parágrafos dos seis textos de cada corpus, segundo o critério da amostra equiprobabilística simples sem reposição (tabela de Kendall \& Smith, 1972).

A informatização dos textos foi feita por escaneamento, utilizando o OCR (Reconhecimento Ótico de Caracteres); também se procedeu à revisão dos textos escaneados, com a correção de caracteres erroneamente reconhecidos pelo OCR. O estudo foi realizado semi-automaticamente, por meio de uma combinação do auxílio das ferramentas fornecida pelo software Multiconcord, pelo programa Conta e por análise manual.

O programa Multiconcord, criado por David Woolls, da Universidade de Birmingham, trabalha com corpus paralelo. Esse software permitiu fazer o alinhamento e numeração dos parágrafos sorteados dos TOS e dos respectivos TTs, facilitando a classificação dos dados.

Todos os segmentos analisados da LP receberam dois tipos de informação por meio de dois números, separados por um ponto e colocados entre parênteses antes do item lexical ou segmento do TO. Os algarismos à esquerda do ponto correspondem ao número de código da modalidade; os à direita, ao número de itens lexicais do original passados para a LC

\footnotetext{
3 A quantidade adotada parece mostrar-se suficientemente representativa para caracterizar cada texto em questão. Conforme atesta AUBERT (1998: 12-13), "most frequently, the model has been applied in describing continuous text segment samples (currently, 500 and 800 words per text selected for corpus sampling). This is the case of Alves (1983), Darin (1986), Silva (1992), Zanotto (1993), Camargo (1993), and Aubert (1984), as well as of" [...] Gehring (1998).
} 
na categoria em questão. Nas modalidades híbridas, registraram-se da mesma forma as co-ocorrências. Na amostra abaixo, extraída dos TO1/ TT1 do corpus de textos literários, tem-se um alinhamento de fragmento de parágrafo do TO e do seu correspondente no TT, com os códigos das modalidades e o número de itens lexicais do TO:

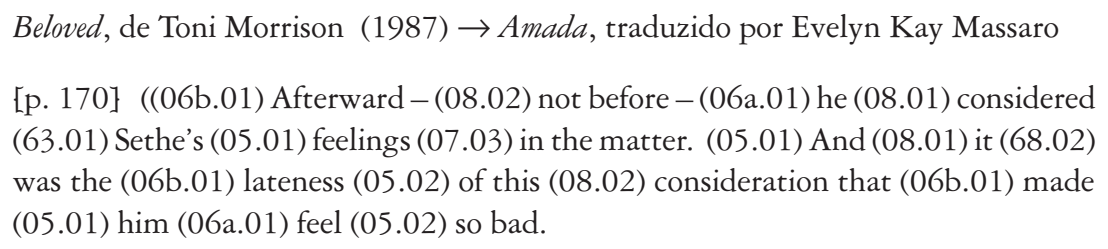

Só muito depois pensara nos sentimentos de Sethe. E o fato de esse pensamento lhe ocorrer tão tardiamente o fizera se sentir mal.

(05.01) Maybe (06a.01) he (08.05) should have left it alone; (08.01) maybe (03.01) Sethe (08.05) would have gotten around to (06a.01) telling (07.01) him (06a.01) herself;

Talvez não devesse ter tocado no assunto. Quem sabe a própria Sethe não iria contar tudo a Paul D (11.06) no momento em que julgasse adequado?

Para a quantificação dos dados utilizou-se o programa Conta, criado pelo grupo de informática do Banco Itaú, de Assis, e adotado pelo Prof Dr. Sérgio Zanoto (2001) para a sua tese de doutorado. Esse programa efetuou a contagem de quantas incidências foram registradas para cada uma das categorias levantadas. Somou todas as ocorrências registradas, exceto os acréscimos. Posteriormente, contabilizou os acréscimos em separado, porquanto a contagem dessa modalidade baseia-se nos itens lexicais do TT. Calculou-se, então, do total obtido para cada modalidade, a proporção do texto na LP que se manifestou na LC.

Com referência à análise dos dados, estabeleceram-se comparações a fim de observar a distribuição absoluta e relativa entre as modalidades tradutórias levantadas no corpus A constituído de textos técnicos, no corpus $\mathrm{B}$ constituído de textos jornalísticos, e no corpus $\mathrm{C}$ constituído de textos literários. 


\section{Resultados e discussão}

A confrontação dos dezoito textos mostrou o predomínio da uniformidade quanto a três categorias de maior freqüência: a tradução literal, a transposição e a modulação. A fim de poder observar a distribuição absoluta e relativa entre as categorias, elaborou-se a tabela abaixo:

\begin{tabular}{c|c|c|c|r|r|r|r|r|r|r|r}
\hline \multicolumn{3}{c|}{ TEXTOS TÉCNICOS } & \multicolumn{3}{c|}{ TEXTOS JORNALÍSTICOS } & \multicolumn{3}{|c}{ TEXTOS LITERÁRIOS } \\
\hline $\begin{array}{c}\text { Classifi- } \\
\text { cação }\end{array}$ & $\begin{array}{c}\text { Có- } \\
\text { digo }\end{array}$ & N. $^{\circ}$ & $\%$ & $\begin{array}{c}\text { Classifi- } \\
\text { cação }\end{array}$ & $\begin{array}{c}\text { Có- } \\
\text { digo }\end{array}$ & N. $^{\circ}$ & $\%$ & $\begin{array}{c}\text { Classifi- } \\
\text { cação }\end{array}$ & $\begin{array}{c}\text { Có- } \\
\text { digo }\end{array}$ & N. $^{\circ}$ & $\%$ \\
\hline $1^{\circ}$ & 05 & 1188 & 39,6 & $1^{\circ}$ & 05 & 1360 & 45,3 & $1^{\circ}$ & 05 & 1048 & 34,9 \\
\hline $2^{\circ}$ & 06 & 875 & 29,2 & $2^{\circ}$ & 06 & 796 & 26,5 & $2^{\circ}$ & 06 & 875 & 29,2 \\
\hline $3^{\circ}$ & 08 & 420 & 14,0 & $3^{\circ}$ & 08 & 396 & 13,2 & $3^{\circ}$ & 08 & 590 & 20,0 \\
\hline $4^{\circ}$ & 07 & 111 & 3,7 & $4^{\circ}$ & 03 & 89 & 2,9 & $4^{\circ}$ & 68 & 163 & 5,4 \\
\hline $5^{\circ}$ & 02 & 104 & 3,5 & $5^{\circ}$ & 01 & 83 & 2,8 & $5^{\circ}$ & 07 & 119 & 4,0 \\
\hline $6^{\circ}$ & 68 & 103 & 3,4 & $6^{\circ}$ & 11 & 81 & 2,7 & $6^{\circ}$ & 01 & 78 & 2,6 \\
\hline $7^{\circ}$ & 01 & 79 & 2,6 & $7^{\circ}$ & 68 & 80 & 2,7 & $7^{\circ}$ & 03 & 70 & 2,3 \\
\hline $8^{\circ}$ & 11 & 50 & 1,6 & $8^{\circ}$ & 07 & 68 & 2,3 & $8^{\circ}$ & 11 & 45 & 1,5 \\
\hline
\end{tabular}

TOTAL DOS TRÊS CORPORA

\begin{tabular}{c|c|c|c|c|c|c|c}
\hline $\begin{array}{c}\text { Classifi- } \\
\text { cação }\end{array}$ & Código & N. ${ }^{\circ}$ & $\%$ & $\begin{array}{c}\text { Classifi- } \\
\text { cação }\end{array}$ & Código & N. ${ }^{\circ}$ & $\%$ \\
\hline $1^{\circ}$ & 05 & 3596 & 40,0 & $5^{\circ}$ & 07 & 298 & 3,3 \\
\hline $2^{\circ}$ & 06 & 2546 & 28,3 & $6^{\circ}$ & 01 & 240 & 2,7 \\
\hline $3^{\circ}$ & 08 & 1406 & 15,6 & $7^{\circ}$ & 03 & 180 & 2,0 \\
\hline $4^{\circ}$ & 68 & 346 & 3,8 & $8^{\circ}$ & 11 & 176 & 2,0 \\
\hline
\end{tabular}

Tabela - Distribuição absoluta e relativa entre as modalidades de maior freqüência nas traduções dos três corpora, por ordem de classificação

Com base no cálculo estatístico, observa-se que a (05) tradução literal é a que se destaca pela maior freqüência, com 39,6\%, 45,3\% e 34,9\%, respectivamente na média geral dos textos técnicos, jornalísticos e literários, e com: 40,0\% no total geral. Essa categoria ocorre quando as palavras ou seqüências de tradução apresentam uma estreita correspondência lexical e têm exatamente a mesma estrutura, ou seja, as mesmas classes gramaticais 
e a mesma ordem do TO. Contando os itens lexicais levantados, pode-se encontrar uma extensão sensivelmente maior do que nas outras modalidades, como no seguinte exemplo, extraído de uma das amostras do corpus B referente aos textos jornalísticos ${ }^{4}$ :

Corpus B: TO5, § 19: sort $(05.10)^{5}$ of memory can be involuntarily revived with terrible clarity by abnormal activity in the (05.01) amygdala.

TT5: uma espécie de pilha de memória pode ser involuntariamente revivida com terrivel clareza por uma atividade anormal da amigdala.

[Segmento longo contendo dez traduções palavra por palavra.]

Embora Nida $(1964,1975)$ enfatize que as transmutações culturais ou adaptações seriam as mais comuns no ato tradutório e Vinay (1976:168) proponha que se deveria evitar o uso da tradução literal devido ao perigo de falsos cognatos, os dados da pesquisa mostram que é uma modalidade largamente empregada a nível de unidades lexicais.

Apresenta-se a segunda maior ocorrência com a (06) transposição, com 29,2\% nos textos técnicos, 26,5\% nos jornalísticos, e 29,2\% nos literários, e com: $28,3 \%$ no total geral. Essa categoria ocorre quando houver mudança de classe gramatical, fusão ou desdobramento, inversões de ordem, ou combinação dessas alterações; não existem, contudo, modificações no sentido ou estilo. Para melhor examinar os casos registrados, subdividiu-se essa modalidade em (06a) transposição obrigatória (utilizada devido a restrições estruturais da LC) e (06b) transposição facultativa (empregada por opção do tradutor, ao julgar que uma tradução literal seria menos adequada). Considerada isoladamente, a transposição obrigatória corresponde à segunda maior porcentagem em cada um dos textos, respectivamente com $24,2 \%, 24,7 \%$ e $25,0 \%$. Já com a transposição facultativa, obtém-se um número consideravelmente menor, respectivamente $4,9 \%, 1,9 \%$ e $4,2 \%$. No exemplo abaixo, pode-se observar uma ocorrência de sete transposições obrigatórias para duas transposições facultativas:

\footnotetext{
4 Nas Referências Bibliográficas: item A) Textos selecionados para análise nos três corpora, encontram-se elencados os títulos dos textos utilizados para a exemplificação.

5 Para facilitar a visualização, a seqüência de itens lexicais referentes à exemplificação das modalidades está grafada em itálico.
} 
Corpus B: TO1, § 1: the (06a.01) tactical fighter AMX being (06b.02) developed jointly (06a.01) by Embraer (06a.04) will have not only Rolls Royce engines but also (06a.01) ejection seats ...

TT1, § 1: o caça tático AMX, em desenvolvimento conjunto pela Embraer, não apenas terá turbinas Rolls Royce assim como assentos ejetáveis ...

[Ajustes lingüísticos obrigatórios na LC: em tactical fighter $\rightarrow$ caça tático, e em ejection seats $\rightarrow$ assentos ejetáveis ocorre uma inversão de ordem pela posposição do adjetivo; já em by $\rightarrow$ pela, o ajuste dá-se pela contração da preposição com o artigo.]

[Combinação tanto de fusão obrigatória de dois termos na LP correspondendo a um na LC: will have $\rightarrow$ terá, como também de mudança de ordem dos advérbios antes do verbo na LC: will have not only $\rightarrow$ não apenas terá.]

[Mudança opcional pelo tradutor de classe gramatical: verbo + advérbio na LP para substantivo + adjetivo na LC: developed jointly $\rightarrow$ desenvolvimento conjunto.]

Com base no total geral dos corpora com 9.000 itens lexicais, têm-se duas categorias básicas empregadas nos três tipos de textos, correspondendo a 3.596 traduções literais e 2.546 transposições, ou seja, a mais da metade da extensão relativa entre as modalidades tradutórias (6.142 itens lexicais $=68,2 \%)$.

Em terceiro lugar, tem-se a (08) modulação nos textos técnicos com $14,0 \%$, nos jornalísticos com $13,2 \%$, e nos literários com 20\%, e com: $15,6 \%$ no total geral. Essa categoria ocorre sempre que um determinado segmento textual for traduzido de modo a impor um deslocamento perceptível na estrutura semântica de superfície, embora retenha o mesmo efeito geral de sentido no contexto e no co-texto específicos. Ex.:

Corpus C: TO5, p. 122: "I'll (08.03) tell you what."

TT5: - Vamos fazer uma coisa.

[Tem-se uma equivalência situacional, por preferência do tradutor.]

Como já era previsto, as amostras dos textos literários parecem solicitar dos tradutores um maior emprego da modulação do que as dos textos técnicos, na medida em que se supõe a linguagem literarária ser mais elaborada do que a utilizada na tecnologia. No entanto, o texto jornalístico, ao contrário do esperado, apresenta o menor emprego de modulações em relação aos outros dois corpora, levantando a suposição de que o tradutor 
de jornais e revistas disporia de menor possibilidade de reestruturação dos TTs, por sofrer injunções de tempo mais exíguo do que os demais profissionais.

De acordo com os dados levantados, pode observar-se uma hierarquia ou praxe tradutória quanto às três categorias de maior freqüência nos três corpora. A partir do quarto lugar, surgem as divergências, encontrando-se nessa classificação a co-ocorrência da (68) transposição com modulação com $5,4 \%$ nos textos literários, e com: 3,8\% no total geral. Essa categoria ocorre quando um termo ou expressão modulada encontra-se em outra posição no período da LC. Ex.:

Corpus C: TO4, p. 254: ... and his eyes in the (68.02) harsh hallway light are frantic ...

TT4: ... e seus olhos, à luz impiedosa do corredor, estão desesperados ...

[Tem-se uma transposição, com os adjetivos antepostos ao substantivo na LP e pospostos na LC, e também uma modulação com o deslocamento semântico harsh hallway

$\rightarrow$ impiedosa do corredor.]

Em virtude de a transposição com modulação apresentar, na sua essência, características bastante similares às da modulação, podem estender-se as mesmas considerações feitas acima para tradução literária em relação à tradução técnica, que apresenta 3,4\% de ocorrências no respectivo corpus, e também em relação à tradução jornalística, que registra, contrariamente ao que se supunha para esse corpus, apenas $2,7 \%$ de freqüência.

Por sua vez, a quarta classificação nos textos técnicos cabe à (07) explicitação/implicitação com 3,7\%. Já nos textos literários, essa categoria, ainda que com uma proporção um pouco maior de 4,0\%, ocupa o quinto lugar no respectivo corpus, e no dos textos jornalísticos, com 2,3\%, passa para a oitava classificação. Consiste a (07a) explicitação na substituição de um segmento por nota de rodapé, aposto explicativo, definição, descrição sumária ou extensa. Já a (07b) implicitação corresponde a informações explícitas contidas no TO e identificáveis com determinado segmento textual, tornando-se referências implícitas no TT. Ex.:

Corpus A: TO5\$21: They also purchase milk products $(07 \mathrm{~b} .03)$ that have been enzimatically treated to hydrolyze the lactose; (07a.01) they are labeled low-lactose or lactose reduced. 
TT5: Eles também podem comprar produtos lácteos tratados enzimaticamente para hidrolisar a lactose; esses produtos são denominados pobres em lactose ou com lactose reduzida.

[Elementos da oração adjetiva restritiva desenvolvida no TO "that have been enzimatically treated” apresentam-se, por opção do tradutor, implícitos pela oração adjetiva restritiva reduzida no TT "tratados enzimaticamente".]

[Já em they $\rightarrow$ esses produtos, tem-se, ao invés do pronome sujeito no TO, uma explicitação do referente no TT.]

Aubert considera a explicitação/implicitação uma categoria entre a transposição e a modulação, por abranger mais do que apenas a adequação formal, ou seja, aborda um problema de percepção de significado, sem ocorrer, todavia, mudança do ponto de vista semântico. Devido à maior porcentagem dessa modalidade encontrar-se nas amostras de textos literários e técnicos, poder-se-ia pensar que os tradutores desses dois tipos de texto apresentam ora uma propensão para usar recursos que possam facilitar a compreensão do leitor ora uma inclinação para evitar redundâncias de conteúdos perceptíveis no TT. Em contrapartida, os tradutores de textos jornalísticos, como já observado anteriormente, parecem valer-se mais acentuadamente da literalidade do que de estratégias para tornar determinados segmentos traduzidos com sentido mais explícito ou implícito.

Ainda em quarto lugar, tem-se o (03) empréstimo nos textos jornalísticos, com 2,9\%. Nos textos literários essa modalidade está em sétimo lugar, com 2,3\%, e nos textos técnicos, devido à baixa incidência de $0,7 \%$, cai para a décima posição. O empréstimo constitui um processo tradutório efetivo, porquanto o segmento inexistente na LC contém uma marca da cultura da LP. Aubert diferencia-o da simples transcrição, porque, no empréstimo, o termo novo mostra-se sempre como um desvio em relação à LC, sem o ser, porém, na LP. Freqüentemente, apresenta-se em itálico ou com aspas, grifos, etc. Ex.:

Corpus B: TO1, $\S 14:$ A number of Distributors were invited to comment (03.02) on camera about what AT\&T can do to be a better global company.

TT1: Um número de distribuidores foram convidados a opinar on camera a respeito do que a AT\&T pode fazer para ser uma empresa global melhor.

[O termo emprestado da LP apresenta-se grafado em itálico no TT.] 
O empréstimo pode representar uma economia de tempo para o tradutor ao invés de recorrer a uma solução mais complexa envolvendo adaptações; daí, talvez, a sua maior incidência nos textos jornalísticos. Também o empréstimo pode ser utilizado pelo tradutor literário para passar a "cor local” pretendida pelo autor do TO. Já o número reduzido de ocorrências nos textos técnicos poderia ser atribuído à necessidade de utilização de uma terminologia específica nas diversas subáreas; conseqüentemente, empréstimos do léxico especializado da LP, ao serem incluídos em dicionários reconhecidamente completos da LC, passam a ser classificados como tradução literal, contribuindo, dessa forma, para aumentar a incidência da categoria de maior freqüência no corpus.

$\mathrm{Na}$ distribuição geral, as outras modalidades, segundo o levantamento de dados, mostram porcentagens bastante reduzidas nos textos considerados como um todo. Quanto à [09] adaptação, categoria situada no outro extremo da escala tradutória em relação ao empréstimo, poderia esperarse uma grande incidência desse procedimento nas amostras que envolvem as traduções literárias e jornalísticas devido à ênfase dada por alguns estudiosos da tradução, considerando-a como a "marca" do bom tradutor pelo grau de dificuldade que apresenta (Vinay 1966:176). Todavia, não se registrou nenhuma ocorrência dessa categoria no corpus de textos jornalísticos. Nos outros dois corpora, levantaram-se somente três ocorrências, com $0,1 \%$, tanto nos textos literários como nos textos técnicos, correspondendo a apenas $0,07 \%$ do total geral da amostragem. A adaptação denota uma assimilação cultural, ou seja, a solução tradutória adotada para o segmento textual dado estabelece uma equivalência parcial de sentido, tida por suficiente para os fins do ato tradutório em questão, mediante uma interseção de traços pertinentes de sentido, mas abandona qualquer ilusão de equivalência 'perfeita'. Ex.:

County: Harris. City or (09.01) Town $\rightarrow$ Condado: Harris. Cidade ou Vila.

[Há apenas uma semelhança parcial entre town $\rightarrow$ vila.]

A esse respeito, o conjunto das modalidades nos três corpora em análise e também os resultados das investigações anteriores integrantes da linha de pesquisa do CITRAT/USP levam a supor que haveria, na prática tradutória, uma distribuição consideravelmente menor da adaptação, e que seu emprego seria bem menos freqüente do que o suposto pelos teóricos, 
dentre eles Nida (1964, 1975), mesmo em se tratando da tradução literária ou jornalística. Outrossim, essas mesmas observações poderiam ser feitas para a (69) transposição com modulą̧ão, porquanto não se detectou nenhuma ocorrência dessa categoria nas amostras examinadas.

Considerando cada texto do corpus isoladamente, pode-se novamente constatar o predomínio da uniformidade quanto às três categorias de maior ocorrência. Vistos em separado, quatro dos seis textos técnicos mostram predominância da regularidade quanto às três modalidades mais recorrentes. Destaca-se, porém, o TT4 sobre 'Prática Dentária', como consideravelmente desviante, por apresentar a transposição (40,2\%) como a categoria mais utilizada, seguida, ainda que com pouca diferença, da tradução literal $(39,6 \%)$. Também revela comportamento desviante a amostra referente ao TT1 'Instruções de Uso do Relógio Seiko', com a transcrição $(8,2 \%)$ em terceiro lugar. No entanto, a dispersão das ocorrências nesses dois textos mostra-se diluída quando da somatória dos seis textos, indicando a tradução técnica uma propensão maior para a literalidade do que para deslocamentos semânticos ou estilísticos.

Por sua vez, nota-se que, vistos separadamente, todos os seis textos jornalísticos evidenciam uma regularidade do corpus quanto às três categorias de maior freqüência, quebrando-se tal concordância a partir da quarta categoria em ocorrência. Acredita-se que as condições de produção de jornais e revistas e a decorrente premência do prazo levariam ao maior índice de automatismos observado: aproximadamente metade das ocorrências em cada um dos seis textos (TT1 'Primeira Conferência Internacional...' $: 50 \%$, TT2 ‘...Cães Pensam...': 40\%, TT3 '...Abelhas-dinossauros': 43,4\%, TT4 'Bill Gates...': 46\%, TT5 'Cérebro...': 50,8\% e TT6 'Sérvios...': 41,8\%), e também em relação a esse corpus $45,3 \%$ correspondem à tradução literal.

Tomando isoladamente cada um dos seis textos literários, constata-se a uniformidade quanto à tradução literal, seguida da transposição e da modulação. Como quarta modalidade, encontra-se a transposição com modulação nos TT2 Lições de Vida (6,2\%), TT4 Coelho Cai (9,8\%) e TT5 Amor sem Igual (6\%). Nos três TTs restantes (TT1 Amada, TT3 A Casa da Rússia, e TT6 Sol Nascente), tem-se uma alteração com o quarto lugar

6 Os título completos dos artigos encontram-se nas Referências Bibliográficas: item A. 
cabendo a outras categorias, já que a transposição com modulação mantém o quinto lugar. Já o TT5 exibe uma flutuação interna dada a diferença de apenas dois itens lexicais entre a categoria de maior emprego, a tradução literal (152 ocorrências, com 30,4\%) e a transposição (150 ocorrências, com 30\%). Desse modo, demonstra a tradução literária uma predominância pela tradução palavra por palavra bem como uma grande propensão para o emprego, na LC, de deslocamentos na seqüência textual ou mudança de classe gramatical.

\section{Considerações finais}

De acordo com as observações acima, pôde-se, por meio da aplicação da proposta de reformulação de Aubert, baseada no modelo descritivocomparativo de Vinay \& Darbelnet, quantificar o grau de intervenção ou mediação exercido pelos tradutores na transferência ou transformação da mensagem da LP para a LC num universo de amostragem de três tipologias textuais distintas. Ainda que no processo tradutório estejam convergindo, de maneira geralmente indissociável, questões lingüísticas, antropológicas, culturais, sociais, psicológicas, ideológicas, etc., ao admitir-se que os primeiros dados de uma tradução são dados lingüísticos se reestabelece a relevância de uma abordagem 'mais estritamente lingüística', como a proporcionada pelo emprego do modelo das modalidades de tradução, o qual permitiu o exame das vinte modalidades tradutórias levantadas, num total de nove mil itens lexicais.

Se de um lado o menor uso da tradução literal nos três corpora reporta-se ao de textos literários, de outro lado é a categoria que se destaca, nas amostras desse tipo de texto, como a mais utilizada pelos tradutores profissionais. Com relação ao maior uso da tradução literal nos corpora encontrar-se em textos jornalísticos, poderia atribuir-se que essa maior propensão para a literalidade seria decorrente das pressões de urgência no prazo sobre os tradutores de jornais e revistas para entregarem a matéria traduzida o mais rápido possível, o que não lhes permitiria o tempo suficiente para maiores reelaborações semânticas e estilísticas. Os resultados estariam também indicando que, para esse tipo de texto, os tradutores buscariam opções na LC que são bastante similares às formas da LP. Desse modo, ao empregarem adequadamente a modalidade da tradução literal, executariam sua tarefa principalmente valendo-se de uma correspondência 
lexical bem próxima do inglês e tenderiam a manter, quando possível no português, a mesma ordem e estrutura gramatical.

Em compensação, a maior incidência da modulação nos três corpora registra-se nos textos literários, o que revelaria uma propensão para uma atuação mais ativa da parte do profissional diante desse tipo de texto. Também o uso mais freqüente dessa modalidade estaria mostrando uma tendência pela qual a tradução literária demandaria uma linguagem menos previsível e mais elaborada, em virtude de um maior uso de figuras de linguagem, ambigüidades, metáforas cristalizadas ou inovadoras, idiomaticidades, construções idioletais, etc.

Por sua vez, o emprego da transposição nos corpora permite notar uma inclinação da parte dos tradutores para recorrerem, freqüentemente, a fusões ou desdobramentos de palavras, a mudanças de classe gramatical e a alterações na seqüência do período, em virtude das exigências impostas pela LC. Contudo, é importante ter-se em mente que a alta incidência observada no emprego da transposição está atrelada ao par de línguas em questão.

Conviria ainda observar que, embora o emprego elevado da tradução literal em textos técnicos e jornalísticos possa indicar menor individualidade por parte dos tradutores, tal inclinação não significa absolutamente maior facilidade na tradução. Nesse sentido, a procura do equivalente mais apropriado, por exemplo, para determinados termos, quer específicos da tecnologia de ponta quer de todo um universo temático abarcado pelos jornais e revistas, poderia ser tarefa muito mais árdua do que encontrar uma rima rica, rara ou preciosa para um dado poema.

Diante da regularidade constatada na distribuição absoluta e relativa entre as modalidades, parece ser viável a existência de uma ordem predominante, na relação inglês $\rightarrow$ português, para as categorias de maior freqüência: tradução literal, transposição e modulação. Conseqüentemente, também se poderia dizer que ocorre certa estabilidade na praxe tradutória com relação aos textos técnicos, jornalísticos e literários com referência a essas três modalidades. Outrossim, dentre as convergências apontadas acima abordando tipologia tradutória em três tipologias textuais distintas, parece destacar-se, como tendência mais nítida, o emprego acentuado da tradução literal. Por sua vez, dentre as similaridades envolvendo a tradução de textos literários, parece evidenciar-se uma propensão direcionada 
para o apelo à modulação, categoria essa que sugere estar tipificando a tradução desse tipo de texto. Diante do exposto, ter-se-ia alguns elementos que permitiriam esboçar traços de uma correlação entre a modalidade da tradução literalltextos técnico e jornalístico, bem como de uma correlação entre as modalidades da modulação e da transposição com modulação/texto literário.

Em face das constatações efetuadas, seria prematuro propor uma aplicabilidade imediata para o ensino e treinamento da tradução. Não obstante, os resultados alcançados permitiram observar um crescimento na distribuição de determinadas categorias consoante os elementos tipológicos, levando a supor-se que tipos de texto diferentes demandariam abordagens tradutórias diferentes, umas mais literais e outras mais criativas. Com base nas tendências apresentadas pelos profissionais, poderia ter-se uma expectativa de uma utilização maior ou menor da categoria da tradução literal bem como de um emprego maior ou menor da modulação conforme os tipos de texto selecionados para serem trabalhados pelos alunos nas disciplinas de prática de tradução. Desse modo, um padrão distributivo das modalidades poderia possibilitar aos estudantes de tradução uma percepção de tendências tradutórias consoante o tipo de texto. Também a prática desta metodologia poderia contribuir para estimular nos futuros tradutores uma conscientização de semelhanças e diferenças entre determinado par lingüístico e cultural. Outrossim, a observação empírica, realizada com bases científicas e sistemáticas, de que a tradução literal é uma modalidade adequada e largamente empregada pelos profissionais revela um aspecto que aponta para o distanciamento entre a teoria e a prática, quando autores, dentre eles Vinay (1976:168) e Nida (1964, 1975), alegam que as transmutações culturais seriam as mais comuns no ato tradutório. Sob esse ângulo, a pesquisa de corpus de textos traduzidos seria uma da possíveis abordagens que poderia trazer dados relevantes para a teoria da tradução, e, talvez, vir a diminuir um pouco a suspeita de uma boa parte dos profissionais em relação à teoria.

Em que pesem as limitações do modelo, o presente estudo facultou uma investigação objetiva e razoavelmente abrangente, ainda que não exaustiva, da freqüência e da distribuição das ocorrências das modalidades tradutórias em três tipologias textuais distintas.

E-mail: diva@lem.ibilce.unesp.br

Recebido em abril de 2002 Aprovado em outubro de 2003 


\section{REFERÊNCIAS BibliográFICAS}

A) Textos selecionados para análise nos três corpora

1. Corpus A - Textos Técnicos ${ }^{7}$ :

TP1: Seiko Quartz - analogue quartz Cal. 6M13 perpetual calendar. Japão: Seiko Corporation, 1991:1-38.

TT1: Seiko Quartz Analógico - calendário perpétuo Cal 6M13. Japão: Seiko Corporation, 1991: 201-239.

TP2: F-prot professional anti-virus software. Estados Unidos: Command Software Systems, 1993: 1-30.

TT2: F-prot professional para DOS. São Paulo: Maple Informática, 1993. sec. $1.1-4.5$.

TP3: Construction/industrial Diesel engines: operation and maintenance manual. Columbus, Indiana: Cummins Engine, 1980. sec. 1.1-4.12.

TT3: Motores Diesel construção/industrial: manual de operação e manutenção. São Paulo: Cummins Brasil, 1983. sec. 1.1 - 5.26.

TP4: SCialfa, Charles T. 1978. Dental practice: electrical stimulation for the treatment of facial parasthesia and pain. Dental Survey. Saint Louis, Missouri, jan.: 42-46.

TT4: Trad. Ivette Roitmann. Prática dentária: estimulação elétrica para o tratamento da dor e parestesia facial. São Paulo, s.d.: 1-5.

TP5: Sutnick, Mona R. 1987 Calories and weight control. The Medical Clinics of North America. v. 71, n. 1. Philadelphia: W.B.Saunders, jan.: 130-133.

TT5: Trad. Dr. Carlos Henrique Cosendey \& Dr. Ismael Lemos. Calorias e controle de peso. Clínicas Médicas da América do Norte. vol. 1. Rio de Janeiro: Interlivros, 1987: 119-122.

TP6: Operator's manual B 58 Volvo. Volvo. s.d.: 1-3.

TT6: Trad. Francis H. Aubert. Manual de operações do Motor Volvo B 58. São Paulo: Volvo. s.d.: 1-3.

2. Corpus B - Textos Jornalísticos ${ }^{8}$ :

TO1: First Annual International Distributor Sales Conference, Power in Partnership, a huge success! ATET's. New Jersey: GBCS's International Distributors, 1995.

\footnotetext{
Nos TT1, TT2 e TT3 técnicos, não consta o nome do tradutor

8 Nos seis TTs jornalísticos, não consta o nome do tradutor.
} 
TT1: Primeira Conferência Internacional Anual de Vendas do Distribuidor, Power in Partnership, um enorme sucesso! São Paulo, 1995.

TO2: The (Secret) World of Dogs. Newsweek. New York, 01/11/93.

TT2: Novo Best Seller Americano Defende a Idéia de que os Cães Pensam, Amam e Têm Alma. O Estado de São Paulo. São Paulo, 14/11/93.

TO3: Nash, J. Madeleine. Return of the Living Dead? Time. New York, 29/05/95: 41-42.

TT3: O Incrível Caso das Abelhas-dinossauros. Manchete. São Paulo, 03/06/95.

TO4: Elmer-Dewitt, Philip. Mine, All Mine. Time. New York, 05/06/95.

TT4: Bill Gates - o senhor do universo. Manchete. São Paulo, 10/06/95.

TO5: Lemonick, Michael D. Glimpses of the Mind. Time. New York, 31/07/95.

TT5: Cérebro - viagem à galáxia dos neurônios. Manchete. São Paulo, 22/07/95.

TO6: Serbs Urged to Sue for Peace after Nato Strike. Financial Times. Londres, 31/08/95.

TT6: Sérvios Aceitam Negociar. Gazeta Mercantil. 31/08/95.

3. Corpus $\mathrm{C}-$ Textos Literários:

TO1: Morrison, Toni. 1987. Beloved. New York, Alfred Knopf.

TT1: Trad.: Evelyn Kay Massaro. Amada. São Paulo, Nova Cultura/Best Seller, s.d.

TO2: TyleR, Anne. 1988. Breathing Lesson. New York, Alfred Knopf.

TT2: Trad.: Wilma Freitas Ronald de Carvalho. Lições de Vida. Rio de Janeiro, Imago.1989.

TO3: Carré, John le. 1988. The Russia House. New York, Alfred Knopf.

TT3: Trad.: Isabel Paquet de Araripe. A Casa da Rússia. Rio de Janeiro, Record, s.d.

TO4: Updike, John. 1990. Rabbit at Rest. New York, Alfred Knopf.

TT4: Trad.: Paulo Henriques Britto. Coelho Cai. São Paulo, Companhia das Letras, 1992.

TO5: Steel, Danielle. 1991. No Greater Love. New York, Delacorte Press.

TT5: Trad.: Aulyde Soares Rodrigues. Amor sem Igual. Rio de Janeiro, Record, 1994.

TO6: Crichton, Michael. 1992. Rising Sun. New York, Alfred Knopf.

TT6: Trad.: Aulyde Soares Rodrigues. Sol Nascente. Rio de Janeiro, Rocco, 1993. 
B) Textos e obras gerais

Alves, Irene da Costa. 1983. Modalidades de Tradução: Uma avaliação do modelo proposto por Vinay e Darbelnet. Dissertação de Mestrado. São Paulo: PUC-SP.

Aubert, Francis Henrik et al. 1984. Descrição e quantificação de dados em Tradutologia. Tradução e Comunicação. 4. São Paulo: Álamo: 71-82. . 1998. Translation modalities - A descriptive model for quantitative studies in Translatology. Romansk Forum. 6. Oslo: Universidade de Oslo: 3-28.

BAKER, Mona. 1993. Corpus Linguistics and Translation Studies: Implications and applications. In: M. Baker; G. Francis \& E. Tognini-Bonelli (Ed.). Text and Technology: In honour of John Sinclair. Amsterdam/ Philadelphia: John Benjamins: 233-250.

. 1997. Non-cognitive constraints and interpreter strategies in political interviews. In: K. Simms (Ed.) Translating Sensitive Texts: Linguistics Aspects. Amsterdam, Rodopi: 111-129.

. 1999. The role of corpora in investigating the linguistic behaviour of professional translators. International Journal of Corpus Linguistics. Manchester.

Camargo, Diva Cardoso de. 1993. Contribuição para uma Tipologia da Tradução: As modalidades de tradução no texto literário. Tese de Doutorado. São Paulo: USP.

Catrord, John Cunnison. 1965. A Linguistic Theory of Translation: An essay in Applied Linguistics. London: Oxford Press. Tradução do Centro de Especialização de Tradutores de Inglês, PUC-Camp. Uma Teoria Lingüística da Tradução. São Paulo: Cultrix, 1980.

CONTA: programa para contagem das modalidades tradutórias. Criado pelo grupo de informática do Banco Itaú, de Assis, e utilizado pelo Prof. Dr. Sérgio Zanoto na sua tese de doutorado, defendida na UNESP/ Assis, 2001.

Darin, Leila C.M. 1986. Translation Modalities in the Comparison of English and Portuguese - Analysis of excerpts taken from C. Castañeda's novel ‘The Teachings of D. Juan' or 'A Erva-do-Diabo”. Dissertação de Mestrado. Exeter: University of Exeter.

Even-ZoHaR, Itamar. 1978. The position of translated literature within the literary polysystem. In: J. S. Holmes; J. LAmbert \& R. van den Broeck. (Ed.). Literature and Translation. Leuven: ACCO, p. 83-100. [Versão revisada em VENUTI, L. (Ed.). The Translation Studies Reader. London/New York: Routledge, 2000: 192-197]. 
FraWley, William. 1984. Prolegomenon to a theory of translation. In: W. Frawley (Ed.). Translation: Literary, linguistic, and philosophical perspectives. London/Toronto: Associated University Presses: 159-175. [Versão revisada em L. VENUTI (Ed.). The Translation Studies Reader. London/New York: Routledge, 2000: 250-263].

Gehring, Sônia. 1998. As Modalidades de Tradução Inglês«Português: correlações bidirecionais. Tese de Doutorado. São Paulo: USP.

Kendall, M.G. \& B. B. Smith. 1985. Randomness and Random Sampling Numbers. In: ARY, D. et al. Introduction to Research in Education. 3. ed. New York: Rinehart and Winston: 430-434.

Magalhães, Célia M. 2001. Pesquisas textuais/discursivas em tradução: O uso de corpora. In: A. Pagano (Org.). Metodologias de Pesquisa em Tradução. Belo Horizonte: FALE-UFMG. cap. 4.

MarcusChi, L. A. 2001. Um corpus lingüístico para a análise de processos na relação fala e escrita. Trabalho apresentado no Simpósio: Corpus Lingüístico, $11^{\circ}$. InPLA, São Paulo, PUC-SP, 4-5 maio 01. Texto digitado, p. 1.

MulticonCord: the Lingua Multilingual Parallel Concordancer for Windows, Birmingham: University of Birmingham.

Newmark, Peter. 1981. Approaches to Translation. Oxford, Pergamon Press. (2a. ed., 1982.)

NiDA, Eugene. 1964. Toward a Science of Translation. Leiden: Brill. . 1975. Language Structure and Translation. California: Stanford University Press.

Pym, Anthony. 1993. Epistemological Problems in Translation and its Teaching. Calaceit (Teruel): Edicions Caminade.

ReIss, Katharina. 1976/1989. Text types, translation types and translation assessment. In: A. Chesterman (Ed.) Readings in Translation Theory. Oy Finn Lectura Ab: 95-115.

Silva, Maria da Graça G.V. 1992. As Modalidades de Tradução Aplicadas ao conto 'O Cobrador': Um estudo comparativo. Dissertação de Mestrado. São Paulo: USP.

Toury, Gideon. 1978. The nature and role of norms in literary translation. In: J. S. Holmes; J. Lambert; \& R. van den Broeck. (Ed.). Literature and Translation. Leuven: ACCO, p. 83-100. [Versão revisada em L. VENUTI (Ed.). The Translation Studies Reader. London/New York: Routledge, 2000: 198-211]. . (1995) Descriptive Translation Studies and Beyond. Tel Aviv, Benjamins Translation Library. 
Tyмосzко, Maria. 1998. Computerized corpora and the future of Translation Studies. Meta. 43:4. Montreal: Les Presses de L’Université de Montreal: 652-659.

Vinay, Jean-Paul. 1968. La Traduction Humaine. In: A. Martinet. Le Langaje. Encyclopédie de la Pléiade. Paris: Gallimard. Trad. p/ Esp. In: A. Martinet. La Traducción Humana. Tratado del Lenguaje. 4. Buenos Aires: Nueva Visión. 1976: 157-185.

VInAY, Jean-Paul. \& Jean Darbelnet. 1958. Stylistique Comparée du Français e de l'Anglais. Paris: Didier, Ed. revista e corrigida,1977. Trad. p/ Inglês: Juan Sager. Comparative Stylistics of French and English - A methodology for translation. Amsterdam/Philadelphia: John Benjamins, 1995.

Woolss, David. Multiconcord: The lingua multilingual parallel concordancer for Windows, Birmingham: Birmingham.

Zanoto, Sérgio A. 2001. As Alices Brasileiras: Um estudo comparativo das traduções do inglês para o português de exertos aleatoriamente escolhidos de Alice's Adventures in Wonderland e Through the Looking-Glass and What Alice Found There. Tese de Doutorado. Assis: UNESP/Assis. Zanotto, Paulo. 1993. Tipos de Texto e Modalidades de Tradução. Tese de Doutorado. São Paulo: USP. 